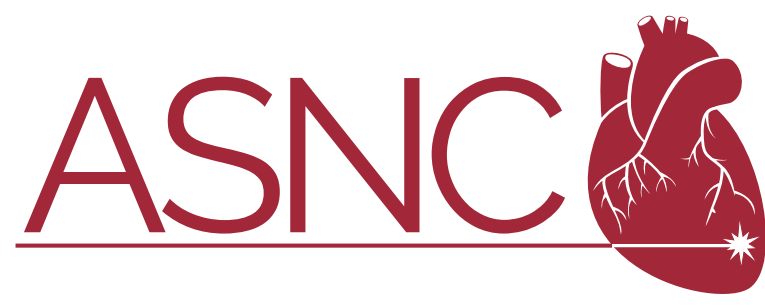

\title{
CALL FOR PAPERS
}

\section{CALL FOR MANUSCRIPTS FOR THEMED ISSUE ON CORONARY MICROVASCULAR DISEASE}

The Journal of Nuclear Cardiology strives to provide a rigorous platform for state-of-the-art and innovative imaging-based solutions. With the changing epidemiology of ischemic heart disease, a themed issue on coronary microvascular disease will be published to review its growing importance in cardiovascular disease management around the world and to highlight the growing role of nuclear cardiology in understanding, diagnosing, and treating coronary microvascular disease.

Manuscripts that address the broad topic of nuclear cardiology and coronary microvascular disease are encouraged. These can be in the form of original research, clinical trials, meta-analysis, or in-depth reviews. Other formats may be considered if they are sufficiently rigorous and impactful. Manuscripts that include correlative imaging approaches (e.g., CT, MRI, echocardiography) to explore implications of CMD on myocardial structure and/or function are also encouraged.
Manuscripts will be processed under a special rapid peer-review and decision process.

Interested authors should submit their papers online at https://mc.manuscriptcentral.com/jnc by December 1, 2021. In the cover letter, please indicate that you would like the submission to be considered for the special issue on coronary microvascular disease.

The final publication is scheduled to appear in JNC in 2022 .

Accepted papers will be available first on the Journal of Nuclear Cardiology website in an "online before print" format.

Marcelo Di Carli, MD, PhD, MASNC

Senior Associate Editor and Guest Editor for the themed issue

Ami E. Iskandrian, MD, MASNC, MACC

Editor-in-Chief

Publisher's Note Springer Nature remains neutral with regard to jurisdictional claims in published maps and institutional affiliations. 